\title{
The ontology of Gero's FBS model of designing
}

\section{Galle, Per}

Published in:

Design Studies

DOI:

10.1016/j.destud.2009.02.002

Publication date:

2009

Document Version:

Peer reviewed version

Link to publication

Citation for pulished version (APA):

Galle, P. (2009). The ontology of Gero's FBS model of designing. Design Studies, 30(4), 321-339.

https://doi.org/10.1016/j.destud.2009.02.002

\section{General rights}

Copyright and moral rights for the publications made accessible in the public portal are retained by the authors and/or other copyright owners and it is a condition of accessing publications that users recognise and abide by the legal requirements associated with these rights.

- Users may download and print one copy of any publication from the public portal for the purpose of private study or research.

- You may not further distribute the material or use it for any profit-making activity or commercial gain

- You may freely distribute the URL identifying the publication in the public portal ? 


\section{The ontology of Gero's FBS model of designing}

Per Galle, Danish Centre for Design Research, Centre for Philosophy \& Design, The Danish Design School, Strandboulevarden 47, DK-2100 Copenhagen O, Denmark

Abstract: Recent work by Pieter Vermaas and Kees Dorst has led to constructive criticism and conceptual clarification of John Gero's FBS (Function-BehaviourStructure) model of designing. In this paper Vermaas' and Dorst's version of the model is scrutinized, with an emphasis on its temporal aspect and ontological implications. Regarding the latter, the model is found to be in need of amendment and further refinement to ensure its clarity and logical coherence. To this end, two alternative modifications of the model are developed. These results are not claimed to be of immediate practical use to designers. Rather, they are intended to contribute to a reliable conceptual foundation for research and tool development that may aim more directly at supporting design practice.

Keywords: Design model; design theory; ontology; philosophy of design.

Paper accepted 2009-02-24 for publication in Design Studies.

This document is the author's accepted manuscript (author's version: 2.2, 2009-03-26), including all revisions public web site under the terms of Elsevier's Journal Publishing Agroesment (reference JDST 537) concerning "Retention of rights for scholarly purposes", according to which terms the following notice is mandatory:

"NOTICE: this is the author's version of a work that was accepted for publication in Design Studies. Changes quality control mechanisms may not be reflected in this document. Changes may have been made to this work since was submitted for publication. A definitive version was subsequently published in Design Studies,
http://dx.doi.org/10.1016/idestud.2009.02.002."
Table of contents

The ontology of Gero's FBS model of designing

[0. Introduction]

1. The FBS model of designing: versions, merits, and shortcomings ......................... 4

1.1. Gero's FBS model and Vermaas \& Dorst's modification................................. 5

1.2. Merits of the model (modified and original) to be preserved ............................ 6

1.3. A problem concerning time, existence, and reference ……………................. 8

2. Two interpretations of the model....................

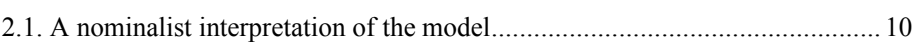

2.2. A realist interpretation of the model........................................................... 12

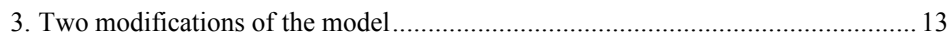

3.1. A nominalist modification of the model .................................................... 14

3.2. A realist modification of the model.............................................................. 16

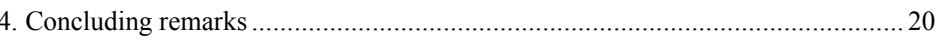

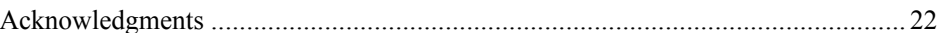

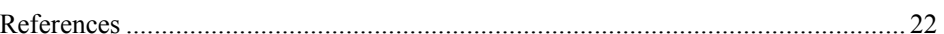

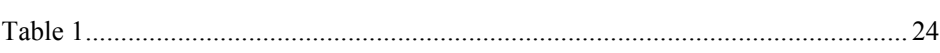

Table 2

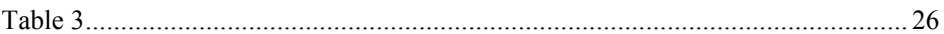

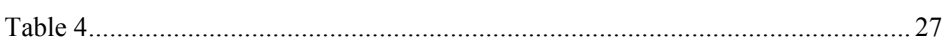

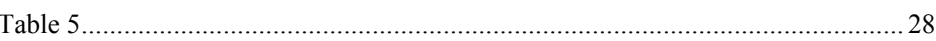




\section{[0. Introduction]}

Design theory is theory that conveys an understanding about what design is or should be; and about how design is or should be carried out. Such understanding may be considered an end in itself (simply satisfying intellectual curiosity), or a means for something else: say, for students of design to grasp their subject, for practitioners of design to reflect on and develop their practice, or for researchers to devise tools or methods (computerized or otherwise) for supporting design practice.

Thus design theory may fundamentally influence people's thinking and work; hence it is important that it be logically coherent and conceptually sound. To ensure this, design researchers should occasionally engage in constructive criticism of design theory produced by themselves or by others. I.e., they should conduct a meta-theoretical discourse about design theory already produced.

At a general level, contributing to such discourse is the aim of the present paper. Hence, the results of the analyses that follow will not be of immediate consequence to design practice, but may bear on it indirectly, by whatever influence they may have on design theory of the future.

More specifically, I shall analyse and offer constructive criticism of a particular version of a so-called 'design model', that was proposed in a recent paper by Vermaas \& Dorst (2007) as the result of a meta-theoretical analysis, and subsequent revision, of the 'FBS model' (Function, Behaviour, Structure) developed since 1990 by John Gero and his collaborators (Gero, 1990). In other words, I shall do to the Vermaas \& Dorst model more or less what Vermaas \& Dorst did to Gero's model - hoping that such painstaking scrutiny and incremental revision of design theory will eventually provide a satisfactory and reliable conceptual infrastructure for more practically oriented design research. To keep things as simple as possible, we restrict our discussion to the design of material artefacts, which is what the models in question seem to have been about from the outset.

In section 1 below, the FBS model is briefly introduced in a broader context of design models in general, and Vermaas \& Dorst's modification is outlined. A critical reading of the latter highlights valuable features worth preserving. Particular emphasis is given to the temporal aspect of design as a precursor to artefact-production. In this light, a close look at the model reveals a problem with its underlying ontology ${ }^{1}$ (hence the title of the paper), i.e., with what the model assumes to exist (at particular points in time) For any given artefact to whose design the model was applied, the model seems to have referred to that artefact - hence to have implied its existence - during its design, at which time, however, the artefact in question could not yet have been available.

Section 2 (most of which may be skipped at a cursory reading) describes two attempts to work around this reference problem by suitable reinterpretations of the model. Both attempts fail, which is seen as indicating a need for further revision.

Section 3 therefore presents two alternative reformulations of the Vermaas \& Dorst version, each of which alleviates the reference problem, while preserving the valuable features of the earlier versions of the model.

Section 4 concludes the paper by summarising the results, and briefly discussing the philosophical implications of the two reformulations as regards our conception of design as a discipline, and the nature of its subject matter.

1. The FBS model of designing: versions, merits, and shortcomings Design models constitute a kind of process-oriented design theory according to which design(ing) is understandable as a sequence of distinguishable stages (usually involving iterations and feed-back loops) undertaken to prepare and enable the eventual production of an artefact. Stages such as 'gather information', 'define problem', 'generate solutions', etc. are common. See for example (Kruger \& Cross, 2006, section 2) for an elaborate model of this sort, originally developed by Kruger from empirical data.

A number of closely related design models are based on the assumption that essentially designing 'is reasoning back from statements on functions to statements on the form of the product' (Roozenburg \& Eekels, 1995, p. 55, emphasis added), where the function-

I use the word 'ontology' in one of its broad philosophical senses, to denote a theory about what exists (see, for example, Lacey, 1996, p. 205). Particularly I am interested in the assumptions of this kind on which the various models of design tacitly are, or explicitly could be, based. 
statements are normative ones, concerning a purpose to be served by a desired product (p. 57). Roozenburg \& Eekels themselves expound a model they call the basic design cycle (pp $88 \mathrm{ff}$ ) based on that idea. It is a very general model whose roots they trace far back into the history of design research. For an overview of contemporary work rooted in this tradition of 'function modeling', see Erden et al's (2008) comprehensive survey. ${ }^{2}$

We shall now focus our attention on a particular member of this family of related models with function as their point of departure: the FBS (Function-Behaviour-

Structure) model of designing that has been under development by John Gero and his collaborators since 1990, and its recent modification by Vermaas \& Dorst (Gero, 1990; Vermaas \& Dorst, 2007).

1.1. Gero's FBS model and Vermaas \& Dorst's modification

Gero and collaborators developed their FBS model as a theoretical vehicle for understanding design, and as a conceptual basis for computerized tools intended to support practicing designers. According to the FBS model, designing an artefact involves a series of elementary steps which 'transform', first, the desired function of the artefact (roughly, its purpose) into its expected behaviour (which will bring about the function); then the expected behaviour into a structure (intended to enable the artefact to exhibit the expected behaviour). After further steps of analysing the structure for its actual behaviour (evaluating it against the expected behaviour, and possibly reformulating the expected behaviour) the structure is finally 'transformed' into a design description from which an artefact may be produced (Gero, 1990). ${ }^{3}$ According to Gero, the experiential knowledge about function, behaviour and structure that a designer needs to do all this, is brought together in design prototypes.

What Vermaas and Dorst (2007) did was to subject the various versions of Gero's FBS model as described in the literature, to a critical but constructive philosophical review.

Note that, as their vantage point is one of Artificial Intelligence in design computing, their use of the word 'ontology' differs somewhat from standard philosophical practice.

In Gero's original model only reformulation of the expected behaviour was provided for; later versions of the model include possible reformulation of the structure and the function as well (Gero \& Kannengiesser, 2004)
In their paper, they identify two problems with the model, and propose amendments to solve both of them. Firstly, they observe that the key concepts of the model-notably that of a function of an artefact - had not been stable over the years, and that they did not have satisfactory definitions yet. Secondly, they argue that Gero seems to have claimed a double status for his model as both descriptive of actual designing, and prescriptive of improved designing. However, a prescriptive model should pick out successful cases of designing only; but a descriptive model should cover less successfu ones as well. Hence Gero's claim is untenable, they contend. Vermaas and Dorst's solution to the first problem involves careful redefinition of the key concepts of the model, and a reformulation of its elementary steps to reflect this. The second problem can be sorted out, they suggest, by restricting the two claims to separate aspects of the model: the sequence of elementary steps might be considered descriptive, while the alleged reliance on prototypes might be taken prescriptively as a rational reconstruction of how designers should carry out the steps (op. cit. p 154).

The brief summaries above will not do justice to the comprehensive work by Gero and his colleagues; nor do they bring out the richness and complexity of Vermaas and Dorst's densely argued philosophical analysis of that work. The summaries are merely intended as a background for our discussion, and as an illustration of how a metatheoretical philosophical approach to design may improve the clarity and soundness of our thinking about design and design methodology. ${ }^{4}$ We are now prepared to apply Vermaas and Dorst's general approach of constructive criticism to their work in turn. In so doing, we shall concentrate on the solution they proposed to the first problem (about the instability of the key concepts)

1.2. Merits of the model (modified and original) to be preserved

As a result of their review of Gero's FBS model, Vermaas \& Dorst (2007) revise its three key concepts of function, behaviour, and structure. Table 1 shows the revised definitions by Vermaas \& Dorst. The definition of 'function', they claim, creates a 'conceptual continuity' with other domains of knowledge; i.e. renders the function

$4 \quad$ Vermaas and Dorst's work may be taken as an illustrative example of what it is that justifies the philosophy of design as a discipline in its own right (Galle, 2002). 
concept compatible with similar concepts of function used in biology, psychology, and sociology (p 144). In support of their definition, they argue that this 'opens the door for design methodology to benefit from work done in those [other] domains' (p 147). Incidentally, the Vermaas \& Dorst concept of function is well aligned with the function concept employed by Roozenburg \& Eekels in the above-mentioned 'basic design cycle' (1995, pp. 56-57). We may take this as a good sign, perhaps, of an emerging 'conceptual continuity' within our own domain, design (methodology).

Table 1 to be inserted approximately here. (Tables appear at the end of the manuscript.)

The complete list of elementary design steps in the Vermaas \& Dorst version is given in Table 2. In terms of step names, the sequence is the same as in Gero's model:

formulation, synthesis, analysis, etc. (with possible iterations); but some of the steps differ in their description from Gero's original steps (compare Gero \& Kannengiesser, 2004, pp. 274-275).

\section{Table 2 to be inserted approximately here.}

Vermaas and Dorst observe that in Gero's version of the model, the transition from the intentional concept of purpose to the non-intentional concept of structure ${ }^{5}-$ a transition that seems crucial to any workable model of design (Vermaas \& Dorst, 2007, p. 141) was implicit and scattered over several steps. In the Vermaas \& Dorst version, all three key concepts are deliberately non-intentional. To make the model work, they introduce purpose as an additional intentional concept, and stipulate an initial step from purpose to function. This clean transition from the intentional to the non-intentional basic concepts tidies up the whole model, and facilitates a characterization of the types of knowledge that drive the various steps (op. cit., section 6).

That said, however, it should be noted that as far as the process is concerned, intentionality has not been, and cannot be, isolated to step 1. Even Vermaas and Dorst's

In this context, 'intentional' may be read as 'concerning the designer's aims'. In philosophy, 'intentionality' more generally denotes the quality of mental states (such as desires) in virtue of which they seem to be directed towards, or be about, 'something' - on some views, even when no such entity exists for them to relate to (Jacob, 2008). For example, if I want a fourth bedroom at home, my desire seems to be about 'it', even though currently my house has only three bedrooms. description of step 2 (synthesis) still has a strong intentional flavour. For what can be meant by 'a structure [...] that is to exhibit the functions' (my italics) if not 'a structure [...] that is expected (hoped, intended) to exhibit the functions'? The corresponding passage in Gero \& Kannengiesser (2004, p. 374) reads ' [...] structure (S) that is intended to exhibit [...]' (emphasis added); and leaving out the word 'intended' may conceal, but cannot eliminate, the fact that (apart from trivial cases) the designer's act of synthesis must be governed by such intentional phenomena as expectation or hope or, indeed, intention. For if in step 2, the designer could simply 'jump' from the function(s) decided upon in step 1 to a structure that were guaranteed to 'exhibit' that function (those functions), then there would be no need for any of the steps 3 (analysis) and 4 (the subsequent evaluation of actual behaviour of tentative proposals against desired function(s)). Gero's FBS model reflects the trial-and-error nature of real-life designing, and any reformulation of the model should respect this.

To sum up the analysis so far: I have outlined what I consider the main merits of the Varmaas \& Dorst version: the redefinition of function which ensures (1) 'conceptual continuity' with other disciplines, and (2) the clean separation of intentionality and nonintentionality as regards the basic concepts of purpose (intentional), and function, behaviour and structure (non-intentional). Any further revision of the model should seek to preserve those merits - as well as (3) the tentative nature of synthesis that was more clearly brought out in Gero's version.

1.3. A problem concerning time, existence, and reference

Like all models of design, the FBS model is a general description of a class of complex processes - i.e., a series of events extended in time - that involve design and which, if successful, lead up to the making of an artefact, and eventually its use. However, at the time a given artefact was designed, that artefact had not been made. For essentially, on any plausible conception of designing, " $[\mathrm{t}] \mathrm{o}$ design is to plan for the making of something new' as Goldschmidt very succinctly put it (1991); so 'designing something already made' (i.e., something not new), would be a contradiction-in-terms.

Admittedly, a somewhat complex artefact $A$ may be seen as composed of parts, and some parts of $A$ may have been made (brought into existence) while designing was still 
in progress to prepare the making of other parts of $A$. But even so, $A$ as a whole would not have been made (brought into existence as $A$ ) until after its design as a whole (the design of all parts of $A$ ) had been completed. In that sense, designing is always prior to making.

Furthermore, to be of any practical and methodical use, the FBS model of designing (as well as any other model of designing) must apply to a design process while it takes place. It is not enough for the model to enable us, after the making of an artefact, to see whether or not the process that led to the making of the artefact, in fact followed the steps of the model. We must be able while designing, to decide whether or not we are doing so in accordance with the model; indeed if we are using tools (computerized design support systems, for example) based on the model, we must be able deliberately to follow the steps of the model in order to make use of those tools.

Hence, for the model to have been working and making sense at the time a given artefact was being designed, the model cannot have assumed the existence of that artefact itself. And the same assumption is precluded because, as we saw, designing is prior to making.

Yet such an assumption is precisely what the FBS model in its present form seems to imply, in view of the many occurrences of the term 'the artefact' in the model. ${ }^{6}$ What are we to make of these ontologically spurious references? How can we defuse the threat they seem to make to the logical coherence of the model?

\section{Two interpretations of the model}

The 'spurious references' we encountered may be dealt with in several ways. Let us begin by assuming that basically the model is all right as it stands, and that the reference problem merely calls for a reinterpretation of the model. In other words, let us try to explain the problem away, rather than attacking it head-on.

6 The problem of the apparent reference to an artefact that is not yet there to be referred to, is similar in nature to what Galle (1999, pp. $65 \mathrm{ff}$ ) has termed 'the problem of the absent artefact' in his analysis of the nature of design representations.
One approach, then, is to consider the problematic references as merely apparent; to talk about descriptions, rather than what appears to be described. We shall call this a nominalist approach, since it amounts to the ontological strategy of explaining away apparent existence claims in terms of language, as a mere play with names and nominal phrases.

Alternatively, we may adopt a realist approach, i.e. the ontological strategy of granting the names or phrases genuine reference to something real (i.e., something that exists; be it concrete entities such as nuts and bolts, mental ones such as thoughts, or abstract ones such as numbers, for example ${ }^{7}$ ). For this to eliminate our reference problem, however, we must look for suitable entities for the model to refer to that are available at the time of designing.

In subsections 2.1 and 2.2 we try these approaches in turn. On a cursory reading they may be skipped, as the results are briefly summarized in section 3 .

\subsection{A nominalist interpretation of the model}

Let us attempt a 'charitable reading' of the model, taking it less literally than we did at first. Rather than seeing 'F', 'B', 'S' and 'function' ('dispositions'), 'behaviour' and 'structure' as referring to actual entities associated with an artefact, we might take these terms to stand for function-descriptions (disposition-descriptions), behaviourdescriptions, and structure-descriptions, respectively (compare Tables 1 and 2). On such a reading, which may seem rather obvious, the model ceases to be about ontologically dubious entities related in obscure ways to an artefact that is not available; instead it becomes a model of a process of symbol manipulation, pure and simple, and thus no artefact needs to be assumed paradoxically prior to its creation. ${ }^{8}$

There are signs already that this may indeed be the understanding of the model that its various authors have had in mind; though not perhaps in a fully conscious way, since

7 The concrete, the mental, and the abstract are examples of basic kinds of entities into which one may classify everything there is. The study of such kinds (known as 'categories') and systems of them is part of the subject matter of ontology, as understood in philosophy.

8 This move is an application of Quine's technique of 'semantic ascent' (Quine, 1960, p. 272). 
the signs are few and far between: (1) In Table 2, the analysis (step 3), denoted ' $S \rightarrow B$ ', is explained as derivation of actual behaviour 'from the description of the structure' (emphasis added). (2) On page 147, Vermaas \& Dorst (2007) say, ' '... whereas in the other steps only physical dispositions and structural descriptions are transformed into one another, or simply compared' (emphasis added). (3) In their rational reconstruction of designing (p 149) they remark that 'Designing starts with intentional purposes and ends, firstly, with a structural description of an artefact by which users can achieve these purposes ...' (italics mine). (4) Gero himself (1990) speaks of his design prototypes in terms of 'dependencies between the variables in the function, structure, behavior categories', where variables are elements of a computerized data structure; hence a sort of description. (5) Similarly, Gero \& Kannengiesser (2004, p. 374) state that 'the basis for Gero's FBS framework is formed by three classes of variables describing different aspects of a design object', namely 'Function (F) variables', 'Behaviour (B) variables', and 'Structure (S) variables'. So again, it appears that the model deals with function, behaviour and structure descriptions, in the form of the (interrelated and coordinated) values of the relevant variables, rather than the function, behaviour and structure themselves.

This is all well and good from an ontological point of view, for surely we can make descriptions that are not descriptions of anything that exists. In this sense, functionbehaviour-, and structure-descriptions in design are no more mysterious than, say, Pegasus-descriptions or Sherlock Holmes-descriptions in mythology and fiction. They make sense even though they do not refer to actual things.

But there is a snag with this approach. For if the authors of the FBS model had meant $S$ to be a structure-description rather than a structure, as suggested above, why would they need step 5, 'Production of the design description'? (See Table 2.) All they would need in order to produce a 'design description' suitable for guiding production of an artefact, would be to iterate the various steps of the model, including the reformulation steps (6, 7 , and 8) long enough for $S$, the structure-description, to become feasible as a basis for artefact-production.
2.2. A realist interpretation of the model

Now let us tentatively assume that 'F', 'B', 'S' and the various phrases with which Vermaas and Dorst summarize their version of the model in Table 2, refer to functions, behaviours and structures that are regarded as entities in their own right even in the absence of, and prior to the making of, any artefact to 'have' them. (They are 'real' in the philosophical sense of being accorded genuine existence, perhaps of the same kind as numbers, sets, and other abstract entities; hence the heading 'a realist interpretation'.)

Thus for example, 'a structure of the artefact that is to exhibit the functions' (Step 2 ) might be read as an expression that refers to an artefact-structure; the phrase that purports to name an artefact merely working as a qualification indicating what kind of structure is being referred to. Similarly, when Step 3 prescribes the derivation of 'the actual behaviour (all the physical dispositions) of the artefact ...', what is really referred to, on this view, is an artefact-behaviour; that is, a number of physical dispositions which, in Step 4, are compared to a more restricted set or collection of physical dispositions, namely the artefact-functions. ${ }^{9}$

Behaviour and functions are physical dispositions, we are told, and physical dispositions can be understood as properties. (Being fire resistant, for example, would be a physical disposition worth considering when designing a party wall between the two dwellings of a semi-detached house. ${ }^{10}$ )

Hence regarding behaviour and function as something that may exist prior to, and independently of any artefact to have them, is not too difficult. All we need is to adopt a

The reinterpretations of 'behaviour of the artefact' as 'artefact-behaviour' (etc.) were modelled on Goodman's analysis of 'picture of Pickwick' and 'picture representing a unicorn' as one-place predicates ('Pickwick-picture' and 'unicorn-picture') picking out certain kinds of pictures, rather than as defective two-place predicates whose second term ('Pickwick' and 'unicorn', respectively) fails to refer (Goodman, 1976, pp. 21-23).

10 Examples of (physical) dispositions often discussed by philosophers are 'being soluble' and 'being fragile'. The notion of dispositions is intuitively clear from a few examples, but rather hard to account for (Fara, 2006). However, here and throughout the paper I make use of them in the same way as Vermaas and Dorst, so in this respect I am neither better nor worse off than they are. 
reading of their definitions in Table 1 in terms of physical artefact-dispositions (again interpreting all talk of 'the artefact' as qualifications indicating a kind of physical dispositions), and an ontology that accommodates such dispositions, qua properties, as entities in their own right.

How about structure, then? Can we conceive of that in a similar way that grants it independent existence? Is there, by analogy to artefact-behaviour and artefact-function, such a thing as artefact-structure without artefact? Unfortunately, the answer seems to be negative, for the following reasons.

If we do to the 'Structure' entry of Table 1 what we just did to the 'Function' and 'Behaviour' entries, the definition of 'Structure' becomes: 'The artefact-materials, the dimensions and geometry of these materials, and their topological relations'. Unlike artefact-function and artefact-behaviour, which conveniently boiled down to properties and thus escaped into the safe and timeless realm of the abstract, artefact-materials are hard to explain away as anything but materials. And the rest of the definition, 'the dimensions and geometry of these materials, and their topological relations', can hardly refer to anything but the materials arranged with such dimensions, geometry and topology as to constitute the artefact whose very existence, as we saw, is precluded at the time of designing.

Even if we trace the definition of 'structure' back to its various earlier forms in Gero's work (Vermaas \& Dorst, 2007, Tables 4, 5, and 6), similar critical remarks apply.

We must conclude therefore, that the FBS model as currently known is not amenable to the remedy of conceiving of artefact-structure as an entity in its own right, i.e., an entity existing prior to and independently of the artefact that will eventually have it (although behaviour and function did lend themselves to such a conception).

\section{Two modifications of the model}

We saw in Section 1.3 that once we took the fact into account that designing an artefact is part of a process extended in time and eventually leading up to the production of the artefact, it became clear how ontologically problematic it is for a design model to refer to that artefact and still remain conceptually coherent and useful during its design. After realising this, we attempted two ways of working around the problem within the existing framework of the FBS model of designing, but so far without success. This does not definitely prove, of course, that a workable solution cannot be contrived within the bounds of the present model; but the obstinacy of the problem nevertheless suggests that it is time to move on, and consider modification of the model itself.

In section 2.1 we entertained the 'nominalist' idea of taking the model to be about descriptions only, about manipulation of symbols. This approach held some promise, except that it called for minor editorial changes of the model so as to eliminate spurious apparent references to a non-existent artefact, and it left the 'documentation step' unaccounted for, or simply made it appear superfluous. In section 3.1 we shall pursue the symbol manipulation idea and explore the changes to the model that will be needed to make it work.

In section 2.2 we considered a 'realist' solution based on conceiving of function, behaviour and structure as entities existing in their own right, even in the absence of any artefact to 'have' them. The proposal nearly worked, but eventually failed because structure, as currently defined, did not lend itself to this approach. It seems worth trying, therefore, to modify the definition of structure so as to make the approach work. We shall return to that in section 3.2 .

\subsection{A nominalist modification of the mode}

Let us adopt once more (as in section 2.1) the nominalist approach to modelling and assume that, properly understood, the FBS model is merely a play with names, withou necessarily anything thereby being named. In particular, we shall assume that nominal phrases such as 'the description of the structure' do not refer to anything beyond a description. Thus, in the example we do not commit ourselves to the existence (at the time of designing) of anything denoted by 'the structure', only to the existence of a structure-description. This time, however, we shall modify the wording of the model accordingly.

Taking the model to be inherently about descriptions, the 'documentation step' (no. 5 in Table 2) becomes redundant, as shown in section 2.1, and we shall therefore omit it in 
the revised version. This in itself amounts to a simplification of the model; something that speaks in favour of the nominalist approach.

Finally, even though function and behaviour might plausibly be stipulated as entities in their own right, as we saw in section 2.2 , we deny them a place in our ontology by assuming only a function-description and a behaviour-description, thereby fully exploiting the conceptual parsimony inherent in nominalism. Accordingly we shall avoid such misleading expressions as 'functions' and 'structures' in our revised formulation of the model. The result of revising the model along these lines is shown in Table 3

Table 3 to be inserted approximately here

The documentation step has been eliminated, and all apparent references to purpose function, behaviour, structure and artefact have been changed into explicit references to descriptions of the relevant kinds (compare Table 1). Nowhere is the existence of any particular artefact assumed or implied.

As it happens, the model in Table 3 bears a striking similarity to the 'basic design cycle' model (Roozenburg \& Eekels, 1995, pp 88 ff; Norbert Roozenburg, personal communication, 2008-05-13). In the basic design cycle, stages are named 'analysis', 'synthesis', 'simulation', 'evaluation', and 'decision'. The first four of these are similar to steps $1-4$ in Table 3. Reformulation steps 5 and 6 , too, have their analogues in the basic design cycle.

Even so, it is worth noting how the present reformulation of the FBS model (explicitly in terms of descriptions) clearly brings out the 'logic of design' underlying the various steps: Step 3 is deductive in nature (reasoning from cause to effect), while Steps 1 and 2 are abductive (reasoning 'backwards' from effect to possible cause).

If Step 4 were extended so as to include a generalization from the descriptions of specific structure-behaviour relationships to more general descriptions (perhaps prototypes as Gero has it), by inductive reasoning, it would become evident that the FBS model (thus modified and augmented) covers very much the same ground as the older 'PDI model' (March, 1976, 1984). March's idea was that designing is an iterative process repeatedly applying production (alias abduction) for describing design proposals (compare the 'synthesis step' in the FBS model); deduction for predicting performance characteristics (compare the 'analysis step' in the FBS model), and induction for evaluation of proposals made so far and generalization of them into suppositions about further proposals that can be made (corresponding to the 'evaluation step' of the FBS model suitably augmented with generation of prototypes). The reformulation steps of the FBS model are what reflect the iterations of March's PDI model.

3.2. A realist modification of the model

Let us return to the realist approach to conceiving of function, behaviour and structure; i.e., to thinking of them as entities in their own right existing for us to refer to at the time of designing. Recall from section 2.2 that our attempt to do so within the framework of Vermaas and Dorst's version of the FBS model failed because their conception of structure did not lend itself to such an interpretation. The main task now is therefore to propose $a$ different structure concept that is genuinely realist.

As a vehicle for this, I propose to use mathematical objects: sets and functions, assuming a so-called Platonist conception of mathematics. Platonism about mathematics is a fairly widely accepted position, though not without competition from other views (Balaguer, 1998). According to mathematical Platonism, mathematics is the study of a rich variety of abstract (non-spatiotemporal) entities, such as sets and numbers, which can be assumed to exist eternally and immutably.

Table 4 lists the main concepts of the realist version of the FBS model I am proposing along these lines. The main idea by which it is distinguished from the Vermaas and Dorst version (Tables 1 and 2) is that a sharp distinction is made between a structure, and material objects embodying that structure. The structure is an abstract, mathematical object (hence timeless and hence always available for us to refer to), whereas the material objects are concrete and of a limited duration. For the sake of conceptual uniformity, function and behaviour are defined as mathematical entities, too.

Table 4 to be inserted approximately here. 
In the model according to Table 4, function, behaviour and structure are conceived of as abstract entities, available for reference at the time of designing, regardless of any material objects. Note also that function is defined in terms of use; this is intended to capture Vermaas and Dorst's idea of a 'use plan analysis of the formulation step', i.e. the step leading from purpose to function (Vermaas \& Dorst, 2007, section 6, particularly note 5$){ }^{1}$

It must not only be conceded but emphasised that the concept of 'material object' proposed in Table 4 may be controversial or in need of refinement. ${ }^{12}$ Particularly when including the temporal clause 'once so arranged and still so arrangeable that', the definition calls for critical scrutiny. One question to consider, for example, would be if a material object possesses the same physical dispositions when disassembled as when assembled; and if not, what that would mean for the definition of function and behaviour? Furthermore, the concept of structure as currently defined, allows materia objects to embody them, which consist of multiple portions of material scattered in space. Is that acceptable, or should restrictions be imposed on structures or otherwise so as to ensure that the material objects picked out be the definition are 'properly composed' in some sense? Rather than trying to fix these issues in an ad-hoc manner, we should see them in the wider context of the metaphysics of material objects in general. That, however, is a notoriously complex subject, which has generated philosophical controversies since antiquity (Lowe, 1998; Simons, 1987), and still does (for two opposed views, see for example Inwagen, 1990; Thomasson, 2007). Even a superficial discussion of the concept of material object in such a wider context would be far beyond the scope of this paper.

For these reasons we shall have to rest content with the proposed concept of a materia object as a mere conjecture. But even so, I submit, it has enough prima facie plausibility

11 Use plans, they explain, 'capture the contexts relative to which it makes sense to speak about functions of artefacts'. The basic idea behind this, namely that 'instructions for use $[\ldots]$ are thought up - together with the form of the product - and thus form an essential part of the design', was mentioned already in (Roozenburg \& Eekels, 1995, p. 58).

12 As it stands, it may itself be regarded a refinement, or development, of the notion of 'regionism' recently proposed in (Galle, 2008, section 6.3.2) to demonstrate the viability of the main idea behind the realist modelling approach: to distinguish between material objects (including artefacts) and their structure; and to conceive of structures as abstract entities, so they are available for us to refer to at the time of designing, and thereby enable us to re-state the FBS model in terms of them without encountering the problems of spurious reference to 'the artefact' that we found in earlier versions of the model.

And yet the critical reader may wonder if by the definitions in Table $4 \mathrm{I}$ merely introduce new kinds of spurious references instead of the one I am trying to escape. Do I not, by my talk of material objects in the definitions of 'function' and 'behaviour', presuppose the existence of such objects at a time where they do not exist - just as I have complained that the Vermaas \& Dorst model presupposes the existence of the artefact prior to its making?

The answer is no, for when I say 'any material object' in the definitions, this is not meant as a universal quantification over a domain of existing entities; rather the phrase is part of a predicate ranging over sets of physical dispositions, and they can be assumed to exist at any time, because dispositions are properties, and we have chosen to conceive of properties as abstract entities. It is possible for a designer to judge whether or not these predicates hold of a certain set of physical dispositions, solely from general knowledge of material objects and the way such objects behave physically and in situations of human use. And we can have such general knowledge without having epistemic access to presently non-existent material objects that might come into existence at some future time. - Much as, say, a geologist may have general knowledge of earthquakes and their consequences for human civilization, regardless of any particular disasters of that sort that the future may have in store for us.

Another critical question that may be raised on the basis of Table 4 is whether a 'set of materials' makes sense? It has been argued that 'worldviews' involving putative sets of perishable entities, such as chairs, are incoherent, on the assumption that sets are timeless and immutable (Galle, 2008, section 2). Perhaps, then, sets of physical substances (the materials) are just as problematic?

Again, the answer is no. Indeed, chemical reactions and other physical processes may create and destroy particular portions of a certain material; but if we think of a materia 
as, say, a system of atoms or molecules organized in a particular way, it becomes as abstract as a geometrical structure (a system of coplanar lines, or of concentric spheres, etc.). By contrast, portions of material are non-permanent, and that is why a material object is conceived of as a collection of such portions, rather than a set. For collections, as opposed to sets, may gain and loose members. (Species, clubs and populations are examples of collections.)

Leaving these discussions aside, we shall now make use of the definitions in Table 4, to re-state the eight steps of the FBS model accordingly. The result is slightly more compact than before, as shown in Table 5 .

Table 5 to be inserted approximately here.

It should be noted that although we have couched the definitions of the three key concepts, function, behaviour, and structure, in mathematical language (Table 4), this does not imply that descriptions actually produced by designers (Table 5 , Step 5 ) will or should make use of mathematical formalism. Conventional sketches, shop drawings, cardboard models, or CAD files that designers traditionally use, will do just as well as they have always done.

But what happened to the artefact in terms of which Vermaas and Dorst, as well as Gero, expressed their versions of the FBS model? If the process captured by Table 5 is successful, any material object which a maker produces from the description $D$ (see Step 5) is a (material) artefact in Hilpinen's sense of an object intentionally made for given purposes (Hilpinen, 2004). This is so because the process as a whole aims at ensuring that the object has physical dispositions that serve the given purposes $(P)$, and because the process as a whole, plus the maker's production of a material object embodying the structure $S$ amounts to intentionally making an object. However, the intention will be on the part of the person or team of human agents carrying out the process outlined by the model. For Hilpinen's definition of 'artefact' to apply, the maker does not have to make the object(s) intentionally. He or she may not know about the purposes of the object(s) he or she is making. In cases of advanced industrial production, the 'maker' may even have been replaced by a CNC machine processing the description $D$ in the form of a computer file, but devoid of any intentions at all.
We could have retained the term 'artefact' in our formulation of the model, to mimic the versions by Gero, and Vermaas \& Dorst. That would be redundant, however; for as just shown, it follows from the formulation of the model that the material object a maker may produce from the description generated according to the model, is an artefact. Hence the shift in terminology.

As we have seen, the present version of the FBS model avoids the problem of reference to an as-yet non-existent artefact (section 1.3) by referring instead to timeless abstract entities: functions and behaviours conceived of as sets of properties, and un-embodied structures conceived of as mathematical functions. In the C-K (Concept-Knowledge) Theory of design (Hatchuel et al., 2004; Hatchuel \& Weil, 2003), 'concepts' would seem to play a role comparable to that of our un-embodied structures. According to C-K Theory, $\mathrm{C}$ is a space of concepts about potential design products (e.g., "bicycles with pedals and effective wings'), while $\mathrm{K}$, the knowledge space, contains knowledge understood as propositions. $\mathrm{K}$ and $\mathrm{C}$ evolve incrementally and in mutual dependence. Unlike propositions, the concepts have no truth-value. 'Concepts are sets from which we cannot extract one element', because if we could 'it would mean that the concept is true for this entity' (Hatchuel \& Weil, 2003, p. 7). That is, at the time of design, concepts are not yet instantiated by physical products. In this respect they resemble our un-embodied structures. However, Hatchuel and Weill draw the conclusion that concepts comply with a version of set theory that rejects The Axiom of Choice, whereas this restriction does not apply to K ( $\mathrm{p} 7$ ). Assuming two versions of Set Theory at the same time is a high price to pay for theoretically handling designers' preoccupation with what does not yet exist. Stipulating abstract entities, such as the un-embodied structures of our present version of the FBS model, as surrogates for artefacts may seem an equally high price to pay. On the other hand, if one has already conceived of ordinary mathematical entities (numbers, sets, etc.) as abstract entities, then adding structures to the list does not seem particularly extravagant.

\section{Concluding remarks}

The motivation for the work reported in this paper is the same that apparently drove Vermaas \& Dorst to propose their amendments to Gero's FBS model of designing: a 
wish to explore and clarify basic conceptual foundations for design research, using the sort of critical concept analysis that is common in philosophy.

I first offered a constructive criticism of Vermaas \& Dorst's version of the FBS model, and identified a problem concerning its ontologically dubious references to an artefact that is not available at the time of designing (section 1.3). Since the problem resisted solution within the framework of the existing model (section 2), I went on to propose two revised versions of the model itself (section 3).

My claim is that both of these new versions (the 'nominalist' and the 'realist' version presented in sections 3.1 and 3.2, respectively) solve the reference problem, while preserving the main ideas of Gero's FBS model, and the particular merits of the Vermaas \& Dorst version (section 1.2): a concept of function that is 'conceptually continuous' with that of other disciplines, and a clean separation of intentional and nonintentional concepts. Furthermore, I re-introduced, in both of my own versions, the explicit recognition of the tentative nature of design synthesis that was present in Gero's model but had slipped out of focus in the Vermaas \& Dorst version (also section 1.2). Thus I believe that the work presented here constitutes a contribution to what in the introduction I called 'a satisfactory and reliable conceptual infrastructure' for design research.

What I do not claim, however, is that any of the model versions I have developed offers final or ultimate answers to the fundamental questions of what designing is, and is about; and no doubt my model versions can be subject to further criticism and improvement in their turn. But let us briefly review them to see what answers to these questions they offer so far, and what their particular merits might be:

- The nominalist model (section 3.1) draws a picture of design as a highly symboloriented or linguistic discipline, concerned with producing sequences of logically interconnected descriptions of various kinds; descriptions that ultimately enable maker to produce an artefact which can be used in accordance with the purposes originally stipulated. The model highlights the logical structure of the reasoning involved in designing (thereby showing its membership of the family of models starting with abductive reasoning from a purpose, a family also including Roozenburg \& Eekels' basic design cycle, and March's PDI model). Furthermore the nominalist model has the advantage of being simpler than its predecessors, in that it could do without an explicit 'documentation step'.

- $\quad$ The realist model (section 3.2) introduces new definitions of the basic concepts of function, behaviour and structure as abstract, mathematical objects, and was furthermore stated in terms of a (conjectured) concept of material objects 'embodying' a given structure. (As suggested earlier, there is a considerable potential for exploration and refinement of this concept of material objects, which in itself might contribute philosophically to our understanding of design of such objects.) In the light of the realist model, the subject matter of design would appear, somewhat superficially and artificially perhaps, as a sort of mathematics; albeit an extremely 'applied' sort, and a sort whose practitioners seldom if ever express themselves in mathematical language! But in that way, design reasoning can be understood as being based on knowledge about structures and their behaviour, which in turn is based on experiential knowledge of the concrete world (hence the qualification 'applied'). Considering this model, we might hope that its mathematical varnish, however thin and artificial it may seem, will turn out to lend a degree of precision to our thinking and theorising about design that could not easily be obtained otherwise.

\section{Acknowledgments}

Thanks are due to two anonymous referees and Regional Editor Norbert Roozenburg, for their thorough reading and constructive criticism of a draft version of this paper.

\section{References}

Balaguer, M. (1998). Platonism and Anti-Platonism in Mathematics. New York, Oxford: Oxford University Press.

Erden, M. S., Komoto, H., van Beek, T. J., d'Amelio, V., Echavarria, E., \& Tomiyama T. (2008). A review of function modeling: approaches and applications.

Artificial Intelligence for Engineeering Design, Analysis and Manufacturing, 22, 147-169.

Fara, M. (2006). Dispositions. Stanford Encyclopedia of Philosophy (Fall 2006 Edition), from http://plato.stanford.edu/archives/fall2006/entries/dispositions 
Galle, P. (1999). Design as intentional action: a conceptual analysis. Design Studies, 20(1), 57-81

Galle, P. (2002). Philosophy of design: an editorial introduction. Design Studies, 23(3), 211-218.

Galle, P. (2008). Candidate worldviews for design theory. Design Studies, 29(3), 267 303.

Gero, J. S. (1990). Design prototypes: a knowledge representation schema for design. AI Magazine, 11(4), 26-36. Retrieved May 14, 2007, from

http://people.arch.usyd.edu.au/ john/publications/1990.html.

Gero, J. S., \& Kannengiesser, U. (2004). The situated function-behaviour-structure framework. Design Studies, 25, 373-391.

Goldschmidt, G. (1991). The Dialectics of Sketching. Creativity Research Journal, 4, No 2, 123-143.

Goodman, N. (1976). Languages of Art. Indianapolis: Hackett Publishing Company. Hatchuel, A., le Masson, P., \& Weil, B. (2004). C-K Theory in practice: lessons from industrial applications. Intern

Hatchuel, A., \& Weil, B. (2003). A new approach of innovative design: an introduction to CK-Theory. International Conference on Engineering Design, ICED 03. Stockholm August 19-21, 2003.

Hilpinen, R. (2004). Artifacts. Stanford Encyclopedia of Philosophy (Fall 2004 Edition), from http://plato.stanford.edu/archives/fall2004/entries/artifact/

Inwagen, P. v. (1990). Material Beings. Ithacha and London: Cornell University Press. cob, P. (2008). Intentionality. Stanford Encyclopedia of Philosophy (Falll 2008 Edition), from http://plato.stanford.edu/archives/fall2008/entries/intentionality/ Kruger, C., \& Cross, N. (2006). Solution driven versus problem driven design: strategies and outcomes. Design Studies, 27, 527-548.

Lacey, A. R. (1996). A Dictionary of Philosophy. London: Routledge.

Lowe, E. J. (1998). Form without matter. Ratio (new series), 9(3), 214-234

March, L. (1976). The logic of design and the question of value. In The Architecture of Form (pp. 1-40). Cambridge: Cambridge University Press.

March, L. (1984). The logic of Design. In Developments in Design Methodology (pp. 265-276). Chichester: John Wiley \& Sons.

Quine, W. V. (1960). Word and Object. New York, London: The Technology Press of the MIT / John Wiley.

Roozenburg, N. F. M., \& Eekels, J. (1995). Product Design: Fundamentals and Methods. Chichester: John Wiley \& Sons.

Simons, P. (1987). Parts. A Study in Ontology. Oxford: Clarendon Press.

Thomasson, A. L. (2007). Ordinary Objects. Oxford: Oxford University Press.

Vermaas, P. E., \& Dorst, K. (2007). On the conceptual framework of John Gero's FBSmodel and the prescriptive aims of design methodology. Design Studies, 28(2), $133-157$.
Table 1

Table 1. FBS definitions according to Vermaas \& Dorst (2007, Table 7)

Functions Those physical dispositions of an artefact that contribute to the purposes for which the artefact is designed

Behaviour The physical dispositions of the artefact

Structure The materials of the artefact, the dimensions and geometry of these materials, and their topological relations 
Table 2. The design steps of the FBS model according to Vermaas \& Dorst (2007, Table 8)

\begin{tabular}{lll}
\hline Step 1: formulation & $P \rightarrow F$ & $\begin{array}{l}\text { Transformation of the client's purposes into } \\
\text { functions (physical dispositions) expected to } \\
\text { contribute to these purposes } \\
\text { Step 2: synthesis }\end{array}$ \\
Step 3: analysis & $S \rightarrow S$ & $\begin{array}{l}\text { Transformation of these functions (these physical } \\
\text { dispositions) into a structure of the artefact that is } \\
\text { to exhibit the functions }\end{array}$ \\
Step 4: evaluation & $B \leftarrow B$ & $\begin{array}{l}\text { Derivation of the actual behaviour (all the } \\
\text { physical dispositions) of the artefact from the } \\
\text { description of the structure }\end{array}$ \\
Step 5: documentation & $S \rightarrow D$ & $\begin{array}{l}\text { Comparison of the actual behaviour and the } \\
\text { functions: do the dispositions of the artefact } \\
\text { include the functions? }\end{array}$ \\
Step 6: reformulation 1 & $S \rightarrow S^{\prime}$ & $\begin{array}{l}\text { Production of the design description } \\
\text { Choice of a new structure }\end{array}$ \\
Step 7: reformulation 2 & $S \rightarrow F^{\prime}$ & $\begin{array}{l}\text { Choice of new functions } \\
\text { Choice of new purposes }\end{array}$ \\
Step 8: reformulation 3 & $S \rightarrow P^{\prime}$ &
\end{tabular}

Table 3. Design steps of the FBS model revised and simplified according to a nominalist approach.

\begin{tabular}{|c|c|c|}
\hline Step 1: formulation & $P \rightarrow F$ & $\begin{array}{l}\text { Transformation of the client's purpose- } \\
\text { description } P \text { into a function-description } F \text { (a } \\
\text { physical-disposition-description) such that } \\
\text { bringing about the truth of } F \text { is expected to } \\
\text { contribute to making } P \text { true. }\end{array}$ \\
\hline Step 2: synthesis & $F \rightarrow S$ & $\begin{array}{l}\text { Transformation of the function-description } F \text { (the } \\
\text { physical-disposition-description) into a structural } \\
\text { artefact-description } S \text { such that bringing about the } \\
\text { truth of } S \text { (i.e., carrying out an act of artefact- } \\
\text { production according to } S \text { ) is expected a to cause } \\
\text { the truth of } F \text {. }\end{array}$ \\
\hline Step 3: analysis & $S \rightarrow B$ & $\begin{array}{l}\text { Derivation of an actual-behaviour-description } \\
\text { (i.e., a physical-disposition-description) } B \text { from } S \\
\text { such that bringing about the truth of } S \text { will bring } \\
\text { about the truth of } B \text {. }\end{array}$ \\
\hline Step 4: evaluation & $B \leftarrow \rightarrow F$ & $\begin{array}{l}\text { Comparison of the actual-behaviour-description } \\
B \text { and the function-description } F: \text { does } B \text { imply } \\
F ?\end{array}$ \\
\hline $\begin{array}{l}\text { Step 5: reformulation } 1 \\
\text { (formerly step 6) }\end{array}$ & $S \rightarrow S^{\prime}$ & Choice of a new structure-description. \\
\hline $\begin{array}{l}\text { Step 6: reformulation } 2 \\
\text { (formerly step 7) }\end{array}$ & $S \rightarrow F^{\prime}$ & Choice of a new function-description, given $S$. \\
\hline $\begin{array}{l}\text { Step 7: reformulation } 3 \\
\text { (formerly step } 8 \text { ) }\end{array}$ & $S \rightarrow P^{\prime}$ & Choice of a new purpose-description, given $S$. \\
\hline
\end{tabular}


Table 4. Key concepts of the FBS model as revised according to a realist approach.

Function serving given purposes: A set of physical dispositions ${ }^{\text {a }}$ such that any material object having them can be used in a way that contributes to the purposes.

Behaviour of a structure: ${ }^{\mathrm{b}}$ The set of physical dispositions, ${ }^{\mathrm{a}}$ which any material object embodying that structure has.

Structure A triple $(R, M, f)$ where $R$ is a finite set of regions of 3D Euclidean space (defined in a given coordinate system), $M$ is a finite set of materials, and $f$ is a total function from $R$ onto $M$.

Material embodying a structure $(R, M, f)$ : A collection of portions of materials in

$M$, once so arranged and still so arrangeable that ${ }^{\mathrm{d}}$ for every $r$ in $R, r$ is occupied by a portion of the material $f(r)$ [in practice: within acc occupied by a portion of the material $f(r)$ [in practice: within acceptable
tolerances].

The dispositions, qua properties, are assumed to exist regardless of their instantiation by material objects. To allow a sound conception of function and behaviour as sets, i.e. abstract entities, the
dispositions must be timeless. If we take them to be abstract entities in the normal sense, they are timeless, but also $\mathrm{c}$, dispute (Fara, 2006, section 5)

b Note that behaviour is defined relatively to a structure, not to a material object.

c The words 'total function', and 'onto', as used in mathematical parlance, ensure that every region in $R$ is assigned precisely one material, and that every material in $M$ is assigned at least one region.

d A shorter and more restrictive version of this clause would read 'so arranged that'; the long version is a conjecture intended to allow for movable objects that leave the system of regions they
Table 5. Design steps of the FBS model revised according to the realist approach based on the concepts defined in Table 4.

\begin{tabular}{|c|c|c|}
\hline Step 1: formulation & $P \rightarrow F$ & $\begin{array}{l}\text { 'Transformation' a of the client's purposes }(P) \\
\text { into a function }(F) \text { serving them. }\end{array}$ \\
\hline Step 2: synthesis & $F \rightarrow S$ & $\begin{array}{l}\text { 'Transformation' a of the function }(F) \text { into a } \\
\text { structure }(S) \text { whose behaviour is expected }{ }^{\mathrm{b}} \text { to } \\
\text { include the function. }\end{array}$ \\
\hline Step 3: analysis & $S \rightarrow B$ & $\begin{array}{l}\text { Derivation of the behaviour }(B)^{\mathrm{c}} \text { of the structure } \\
(S) \text {. }\end{array}$ \\
\hline Step 4: evaluation & $B \leftarrow \rightarrow F$ & $\begin{array}{l}\text { Comparison of behaviour }(B) \text { and the function } \\
(F) \text { : does the behaviour include the function? }\end{array}$ \\
\hline Step 5: documentation & $S \rightarrow D$ & $\begin{array}{l}\text { Production of a description }(D) \text { of the structure } \\
(S) \text { that enables a maker to produce one or more } \\
\text { material objects embodying that structure. }{ }^{\mathrm{d}}\end{array}$ \\
\hline Step 6: reformulation 1 & $S \rightarrow S^{\prime}$ & Choice of a new structure. \\
\hline Step 7: reformulation 2 & $S \rightarrow F^{\prime}$ & Choice of a new function. \\
\hline Step 8: reformulation 3 & $S \rightarrow P^{\prime}$ & Choice of new purposes. \\
\hline \multicolumn{3}{|c|}{$\begin{array}{l}\text { a The word 'transformation' stems from Gero's original formulation and was preserved to } \\
\text { acknowledge the ancestry of the model. Scare quotes are added, however, to indicate that steps } 1 \\
\text { and } 2 \text { do not involve any change into something else, of purposes and function respectively, as the } \\
\text { word might suggest. }\end{array}$} \\
\hline \multicolumn{3}{|c|}{ (1) } \\
\hline \multicolumn{3}{|c|}{$\begin{array}{l}\text { In practice it may be neither possible nor necessary to know all the physical dispositions that make } \\
\text { up the behaviour. It will be sufficient to know the behaviour well enough to carry out Step } 4 \text {. }\end{array}$} \\
\hline $\begin{array}{l}\text { The phrase "material } \\
\text { material; it does not in } \\
\text { production. }\end{array}$ & cts emb & $\begin{array}{l}\text { that structure' refers to a type of arrangements of } \\
\text { (instance) of that type exists prior to the maker's act of }\end{array}$ \\
\hline
\end{tabular}

